Rev. Latinoam. Psicopat. Fund., São Paulo, 20(2),403-406, mar. 2017

http://dx.doi.org/10.1590/1415-4714.2017v20n2p403.13

A mãe eterna: morrer é um direito

Betty Milan

Rio de Janeiro: Record, 2016, 142 págs.

\title{
Poderosos insights
}

402

Marco Antonio Coutinho Jorge*1

Juntamente com as ameaçadoras forças destrutivas da natureza e as dores dilacerantes causadas pelas relações amorosas, Freud situa a decrepitude do corpo como uma das mais importantes fontes de sofrimento do ser humano. A fragilidade do corpo, seu envelhecimento inexorável constituem uma constante ameaça à homeostase psíquica que o narcisismo nos proporciona. Nesse livro, Betty Milan explora com agudeza e profundidade a vivência da filha que se depara com a velhice extrema da mãe e a falência do corpo trazida por essa condição: perda de memória, de audição, de visão, a incontinência e a debilidade dos membros inferiores.

\footnotetext{
${ }^{* 1}$ Universidade do Estado do Rio de Janeiro - UERJ (Rio de Janeiro, RJ. Br).
} 


\section{RESENHAS BIBLIOGRÁFICAS}

Mas não se trata de uma doença física, mas sim do envelhecimento gradual e contínuo que leva a filha a um trabalho de luto em vida: não houve a perda da mãe, mas ao mesmo tempo ela não é mais a mesma: aquela mãe farta de outrora, a mãe doadora. Dessa mãe, agora trata-se de se despedir... em vida!

Assim, não se trata tampouco da morte, mas sim da vida que se esvai na longevidade extrema e que, ao contrário, resiste à morte e inventa a inusitada arte de não morrer. O diálogo estabelecido entre a mãe eterna e a filha terá como tema a vida passada e a morte futura. Como se ambas estivessem imprensadas numa dimensão temporal estranha que exclui o presente e só permite o luto e a rememoração. Esta se torna uma arma poderosa contra o vazio iminente do futuro e o presente, que alude ao desaparecimento é a ocasião propícia para evocar a vitalidade perdida através de cenas do passado, da leitura de cartas e da observação de fotos.

A obra de arte se caracteriza, em sua essência, por transmitir um afeto poderoso, por tocar o espectador; a obra de arte é aquela que afeta, emociona, co-move - quer dizer, move junto - leva o outro ao riso, ao choro e até, em alguns casos, o angustia. Por isso a obra de arte se torna imprescindível, ela nos dá acesso a algo que, de outro modo, teríamos que fazer o mesmo esforço do artista para conquistá-lo.

Esse livro de Betty Milan tem a estrutura de poemas em prosa. Pequenos capítulos que produzem poderosos e contínuos insights, onde se vê a poesia de mãos dadas com a psicanálise, aliança que talvez seja o objetivo mais ambicionado por todos os analistas. Assim como Freud afirmou que a palavra que importa é aquela intimamente conectada ao afeto, Lacan falou da relação intrínseca entre o ato analítico e o ato poético. Alain Didier-Weill — psicanalista francês cuja obra eu tive a alegria de conhecer através da indicação de Betty Milan nos anos 1980 - também ponderou que o analisando constrói na análise seu poema pessoal. Algo que só ele pode dizer e que ninguém mais poderia dizer em seu lugar.

Embora o tema seja o da velhice extrema e da expectativa da morte, o livro tem momentos de grande humor, em que se dá muitas gargalhadas. Ele surpreende por oscilar entre o trágico e o cômico, e nos lembra da frase salutar que Lacan disse certa vez: "A vida seria trágica se não fosse cômica". Por exemplo, o momento em que a filha pergunta se a mãe eterna quer ser velada em casa ou não, cai como um verdadeiro chiste, em que ambas tratam da morte com uma franqueza inédita.

Outro momento hilário: perguntada com que roupa quer ser colocada no caixão, a mãe eterna responde: “ — A roupa branca, o tailleur... Já mandei 


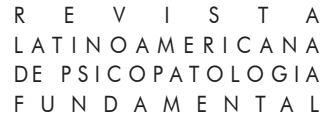

três vezes para o tintureiro". A filha exclama: “ - Três vezes por que? O tailleur está manchado?" "Não, filha... é que eu mando para o tintureiro e depois uso de novo.”! Se a roupa preferida já está separada para o funeral, ao ser usada ela é reincluída no circuito vital. Enquanto há vida, ela deve ser bem vivida.

Como se fosse a colocação em ato das formulações que Freud faz sobre a morte: não há inscrição da morte no inconsciente e, no fundo, nos sentimos imortais. Nessa mesma direção, Marcel Duchamp pediu que fosse inscrita em sua lápide a frase: "Aliás, são sempre os outros que morrem...!" Ao lermos essa frase, nos deparamos com a morte pelo viés exclusivo da morte do outro e, portanto, somos relançados com toda força para o âmbito de nossa vida.

Mas o acompanhamento da morte da mãe eterna, que não vem e que virá, é causa de angústia. Metade do palhaço é riso e a outra metade é choro, diz a filha em determinado momento.

O humor perpassa as diferentes situações e faz lembrar de uma anedota que Freud gostava muito de citar: a do condenado à morte. Quando é chegado o dia, ao ser buscado na cela pelos guardas para ser levado à execução, ele disse: " - Bela maneira de começar o dia!".

A filha faz menção ao budismo, ao Tao e a gente vê que a sabedoria oriental é um verdadeiro ideal para saber lidar com a velhice e a morte. Freud também utilizou a nomenclatura zen para falar da pulsão de morte e introduziu a noção que leva o nome de Princípio de Nirvana.

Nós temos uma atração pela morte - é o que Freud demonstrou. Basta que se veja nossa linguagem cotidiana: estamos sempre morrendo de alguma coisa - morrendo de rir, morrendo de fome, morrendo de tesão... a gente morre de tudo que se relaciona ao melhor e ao pior da vida! A gente diz que alguém "finalmente descansou", "partiu desta para melhor"! Mas a verdade é que a gente prefere é ficar cansados e nesta pior mesmo...

Entre muitos desenvolvimentos apresentados numa escrita concisa que reflete o poder da palavra quando é condensada poeticamente, a questão do filho homem que não está nunca presente me pareceu levantar algo fundamental. A filha se encontra só nessa tarefa de ser a mãe da mãe, o irmão não compartilha isso. Ele se ausenta, nega a situação delicada vivida pela mãe. Por que? - pergunto eu. Trata-se do forte narcisismo masculino que da morte não quer saber? Da fraqueza do homem diante da dor insuportável de se defrontar com a decadência de uma mãe que ele quer eterna? Para ser mãe da mãe é necessário ser mãe? 


\section{RESENHAS BIBLIOGRÁFICAS}

Citação/Citation: Coutinho Jorge, M. A. (2017, junho). Poderosos insights. Resenha do livro A mãe eterna: morrer é um direito. Revista Latinoamericana de Psicopatologia Fundamental, 20(2), 403-406. http://dx.doi.org/10.1590/1415-4714.2017v20n2p403.13

Editores do artigo/Editors: Profa. Dra. Sonia Leite

Recebido/Received: 13.12.2016 / 12.13.2016 Aceito/Accepted: 8.2.2017 / 2.8.2017

Copyright: (C) 2009 Associação Universitária de Pesquisa em Psicopatologia Fundamental/ University Association for Research in Fundamental Psychopathology. Este é um artigo de livre acesso, que permite uso irrestrito, distribuição e reprodução em qualquer meio, desde que o autor e a fonte sejam citados / This is an open-access article, which permits unrestricted use, distribution, and reproduction in any medium, provided the original authors and sources are credited.

\section{Marco Antonio Coutinho Jorge}

Psiquiatra e Psicanalista; Professor Associado do Instituto de Psicologia e do Programa de Pós-graduação em Psicanálise da Universidade do Estado do Rio de Janeiro - UERJ (Rio de Janeiro, RJ. Br); Diretor do Corpo Freudiano Escola de Psicanálise Seção Rio de Janeiro (Rio de Janeiro, RJ. Br); Membro da Association Insistance (Paris/Bruxelas) e da Société Internationale d'Histoire de la Psychiatrie et de la Psychanalyse (Paris, França).

Rua Terezina, 19 - Santa Teresa

20240-310 Rio de Janeiro, RJ, Br

macjorge@corpofreudiano.com.br

This is an open-access article, which permits unrestricted use, distribution, and reproduction in any medium for non-commercial purposes provided the original authors and sources are credited. 